\title{
Metode Enhanced Trinomial Pada Aproksimasi Numerik Pada Barrier Options Pricing
}

\author{
Muhammmad Hasan Asnawi1 ${ }^{1}$ Abdul Aziz ${ }^{2}$ \\ ${ }^{1}$ Mahasiswa Jurusan Matematika, Universitas Islam Negeri Maulana Malik Ibrahim \\ Malang \\ ${ }^{2}$ Dosen Jurusan Matematika, Universitas Islam Negeri Maulana Malik Ibrahim Malang
}

Email: hasan.asnawi6127@gmail.com, abdulazizuinmlg@gmail.com

\begin{abstract}
ABSTRAK
Barrier options pricing sering digunakan dalam jual beli saham karena memiliki harga yang lebih murah dari harga saham plain vanilla option. Dengan menggunakan metode trinomial, didapatkan tiga kemungkinan nilai pergerakan saham yaitu nilai saham naik, turun, dan tetap. Nilai parameter-parameter dari metode trinomial diperoleh dengan menentukan nilai peluang tetapnya $p_{m}=2 / 3$. Selanjutnya dicari nilai peluang naik dan turunnya dengan menyamakan ekspektasi diskrit dengan kontinu dan menyamakan variansi diskrit dengan kontinu. Metode enhanced trinomial merupakan metode trinomial yang nilai sahamnya didekati menggunakan nilai upper dan lower barrier dengan rumus enhanced numerical. Sehingga didapatkan nilai opsi saham yang lebih kecil daripada metode trinomial standar. Oleh karena itu, dengan metode enhanced trinomial nilai opsi saham yang lebih cepat konvergen. hal ini dibuktikan dari simulasi yang telah dilakukan dalam penelitian ini.
\end{abstract}

Kata Kunci: barrier options pricing, saham, metode enhanced trinomial

\begin{abstract}
Barrier options pricing is often used in stock trading because it has a lower price than the plain vanilla option. By using the trinomial method, obtained three possible values of stock movements that are stock value up, down, and fixed. The value of the parameters of the trinomial method is obtained by determining the fixed probability value $p_{m}=2 / 3$. Next look for the value of chance up and down by equating discrete expectations with continuous and equalize discrete continuous variances. The enhanced trinomial method is a trinomial method whose stock value is approximated using upper and lower barrier values with enhanced numerical formula. So the stock value is smaller than the standard trinomial method. Therefore, with enhanced trinomial methods the value of stock options faster converges. this is evidenced from the simulations that have been done in this study.
\end{abstract}

Keywords: barrier option pricing, stock, enhanced trinomial method

\section{PENDAHULUAN}

Saham adalah surat berharga yang merupakan tanda kepemilikan seseorang atau badan terhadap suatu perusahaan. saham juga dapat diartikan sebagai surat berharga yang dikeluarkan oleh perusahaan yang berbentuk Perseroan Terbatas (PT) atau yang biasa disebut emiten. Menjadi pemilik sebagian saham dalam perusahaan berarti juga menjadi pemilik sebagian dari perusahaan itu. Dengan demikian, kalau seorang investor membeli saham, maka ia pun menjadi pemilik atau pemegang perusahaan. 
Exotic option merupakan pengembangan dari plan vanilla option yang lebih kompleks. Barrier options merupakan salah satu jenis exotic option. Pada barrier options pergerakan saham akan memiliki nilai atau dapat di exercise ketika harga saham tersebut memenuhi syarat dari nilai barrier yang telah ditentukan sebelumnya [1].

Model binomial dapat dibangun dengan skema (tree) untuk fluktuasi harga saham secara diskrit, dari skema Gambar 1 dimisalkan harga saham pada saat $t=t_{0}$ adalah $S_{0}=$ $S_{00}=S$, dan harga saham pada saat $t=t_{1}$ adalah $S_{01}=S u$ dan $S_{11}=S d$ [1].

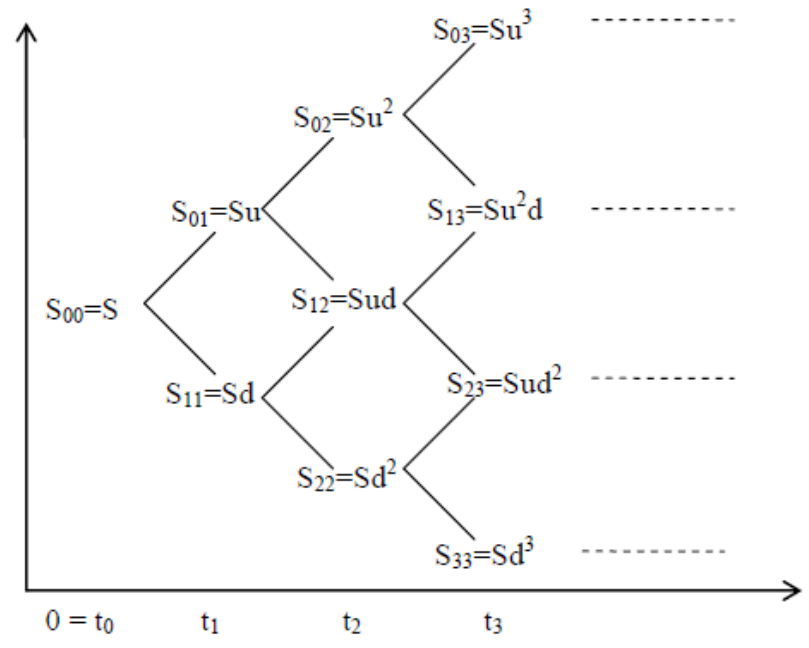

Gambar 1 Skema Fluktuasi Harga Saham Secara Binomial [1]

Sehingga secara umum harga saham pada saat $t=t_{j}$ terdapat $j+1$ kemungkinan dengan rumus umum

$$
S_{i j}=S_{0} u^{j-i} d^{i}, j=0,1, \ldots, M \text { dan } i=0,1, \ldots, j .
$$

sehingga diperoleh nilai-nilai payoff, pada $t=T$, untuk European call option

$$
V_{i M}=\max \left(S_{i M}-K, 0\right) \text {, }
$$

dan untuk European put option

$$
V_{i M}=\max \left(K-S_{i M}, 0\right),
$$

Nilai-nilai option untuk European call option

$$
V_{i j}=e^{-r \Delta t}\left(p V_{i, j+1}+(1-p) V_{i+1, j+1}\right)
$$

dan untuk European put option

$$
V_{i j}=e^{-r \Delta t}\left(p V_{i, j+1}+(1-p) V_{i+1, j+1}\right)
$$

Menurut Stampfli dan Goodman untuk menentukan tiga parameter yang belum diketahui $u, d, p$, diperlukan tiga persamaan, yaitu

1. Menyamakan ekspektasi harga saham model diskrit dengan model kontinu.

2. Menyamakan variansi model diskrit dengan model kontinu.

3. Menyamakan $u \cdot d=1$.

Sehingga nantinya akan didapatkan nilai $u, d$ dan $p$ sebagai berikut

$$
u=e^{\sigma \sqrt{\Delta t}}
$$




$$
\begin{gathered}
d=e^{-\sigma \sqrt{\Delta t}} \\
p=\frac{e^{\sigma \sqrt{\Delta t}}-d}{u-d}
\end{gathered}
$$

nilai-nilai dari parameter-parameter $u, d$ dan $p$ ini telah diperkenalkan oleh Cox, Ross, dan Rubinstein (CRR) sehingga lebih dikenal dengan binomial CRR [2].

Barrier options adalah exotic derivative yang path dependent. Nilainya tergantung pada tingkat level barrier tertentu dan selama periode waktu tertentu. Pasar untuk barrier options telah tumbuh kuat karena mereka lebih murah sesuai pilihan standar dan menyediakan alat bagi risk manager untuk lebih mengekspresikan pandangan pasar mereka tanpa membayar untuk hasil yang tidak sesuai [3].

Beberapa cara dalam penentuan harga opsi barrier sangatlah penting. Oleh karena itu, kita dapat mendefinisikan down-and-in, up-and-in, down-and-out, dan up-and-out untuk pilihan call dan put, sehingga memberikan kita total delapan pilihan barrier options yang berbeda. Kedelapan tipe-tipe barrier options tersebut adalah [3]

1. Down-and-in call option,

$$
C_{d i}\left(S_{T}, T\right)=\left\{\begin{array}{c}
\left(S_{T}-K\right), \quad \text { jika } S_{t}<B, t \in(0, T] \text { (exercised) } \\
0, \quad j i k a \exists t \in(0, T] \ni S_{t} \geq B \text { (expired) }
\end{array}\right.
$$

2. Down-and-out call option,

$$
C_{d o}\left(S_{T}, T\right)=\left\{\begin{array}{c}
\left(S_{T}-K\right), \quad j i k a S_{t}>B, t \in(0, T](\text { exercised }) \\
\left.0, \quad j i k a \exists t \in(0, T] \ni S_{t} \leq B \text { (expired }\right)
\end{array}\right.
$$

3. Up-and-in call option,

$$
C_{u i}\left(S_{T}, T\right)=\left\{\begin{array}{c}
\left(S_{T}-K\right), \quad j i k a S_{t}>B, t \in(0, T](\text { exercised }) \\
0, \quad j i k a \exists t \in(0, T] \ni S_{t} \leq B \text { (expired) }
\end{array}\right.
$$

4. Up-and-out call option,

$$
C_{u o}\left(S_{T}, T\right)=\left\{\begin{array}{c}
\left(S_{T}-K\right), \quad j i k a S_{t}<B, t \in(0, T] \text { (exercised) } \\
0, \quad j i k a \exists t \in(0, T] \ni S_{t} \geq B \text { (expired) }
\end{array}\right.
$$

5. Down-and-in put option,

$$
P_{d i}\left(S_{T}, T\right)=\left\{\begin{array}{c}
\left(K-S_{T}\right), \quad \text { jika } S_{t}<B, t \in(0, T](\text { exercised }) \\
0, \quad j i k a \exists t \in(0, T] \ni S_{t} \geq B \text { (expired) }
\end{array}\right.
$$

6. Down-and-out put option,

$$
P_{d o}\left(S_{T}, T\right)=\left\{\begin{array}{c}
\left(K-S_{T}\right), \quad \text { jika } S_{t}>B, t \in(0, T](\text { exercised }) \\
\left.0, \quad j i k a \exists t \in(0, T] \ni S_{t} \leq B \text { (expired }\right)
\end{array}\right.
$$

7. Up-and-in put option,

8. Up-and-out put option

$$
P_{u i}\left(S_{T}, T\right)=\left\{\begin{array}{c}
\left(K-S_{T}\right), \quad \text { jika } S_{t}>B, t \in(0, T](\text { exercised }) \\
0, \quad j i k a \exists t \in(0, T] \ni S_{t} \leq B \text { (expired) }
\end{array}\right.
$$

$$
P_{u o}\left(S_{T}, T\right)=\left\{\begin{array}{c}
\left(K-S_{T}\right), \quad j i k a S_{t}<B, t \in(0, T](\text { exercised }) \\
0, \quad j i k a \exists t \in(0, T] \ni S_{t} \geq B \text { (expired) }
\end{array}\right.
$$

Dengan memperhitungkan proporsi jarak antara level upper barrier dengan level lower barrier terhadap specified (true) barrier, maka akan diperoleh nilai-nilai option yang lebih baik pada kedua level tersebut. Karena untuk titik-titik yang lebih dekat dengan level true barrier akan diperoleh nilai option yang lebih akurat [4].

Selanjutnya mengganti nilai-nilai pada level upper atau lower barrier, yang memberikan nilai pada barrier options, dengan memberikan rumus pengganti yang dikenal sebagai enhanced numerical [4]: 
Keterangan:

$$
\begin{aligned}
& V *(U)=\left(\frac{U-B}{U-D}\right) V(U) \\
& V *(D)=\left(\frac{B-D}{U-D}\right) V(D)
\end{aligned}
$$

$U=$ nilai saham pada level upper barrier

$D=$ nilai saham pada level lower barrier

$B=$ nilai barrier

$V()=$. nilai hasil perhitungan binomial CRR

Salah satu tantangan dari metode numerik adalah untuk menentukan estimasi galat pada saat tidak adanya ilmu mengenai nilai yang sebenarnya. Contohnya, metode numerik tertentu menggunakan pendekatan iteratif untuk menghitung jawaban. Pada pendekatan seperti ini, aproksimasi sekarang (present approximation) dibuat berdasarkan aproksimasi sebelumnya. Proses ini dilakukan berulang-ulang, atau secara iteratif, untuk memperoleh keberhasilan dalam penghitungan aproksimasi yang lebih baik. Untuk kasus seperti ini, galat sering diestimasikan sebagai selisih antara aproksimasi sebelumnya dan sekarang. Sehingga, didapatkan persamaan galat relatifnya [5]

$$
\varepsilon_{a}=\frac{\text { current approximation }- \text { previous approximation }}{\text { current approximation }}
$$

Pada persamaan (19) ketika nilai pendekataan saat ini lebih besar daripada nilai pendekatan sebelumnya, maka didapatkan nilai error yang positif dan ketika nilai pendekatan saat ini lebih kecil daripada nilai pendekatan sebelumnya maka akan mendapatkan nilai error yang negatif. Ketika melakukan perhitungan, kita tidak memperhatikan tanda pada galat, tapi kita lebih tertarik pada apakah nilai mutlak lebih kecil daripada nilai toleransi $\varepsilon_{s}$. Oleh karena itu, persamaan (19) yang sering digunakan adalah nilai mutlaknya. Untuk kasus seperti ini, perhitungan akan terus diulang sampai

$$
\left|\varepsilon_{a}\right|<\varepsilon_{s}
$$

Jika hubungan ini terpenuhi, maka diasumsikan hasilnya diterima dalam tingkat $\varepsilon_{S}$ [5].

Untuk mendekati nilai saham yang kontinu digunakanlah metode numerik yang sering digunakan yaitu metode binomial. Metode binomial memiliki dua nilai yang memperlihatkan naik turunnya harga saham pada setiap periode. Namun, pada kenyataannya pada setiap periode juga terjadi harga saham yang meliki nilai tetap terhadap saham sebelumnya. Oleh karena itu dikembangkanlah model perhitungan harga saham menggunakan metode trinomial yang memiliki tiga nilai saham yaitu nilai saham naik, turun dan tetap.

\section{METODE}

Adapun langkah-langkah yang digunakan dalam penelitian ini adalah

1. Penentuan parameter metode trinomial

2. Simulasi numerik metode standar trinomial dan enhanced trinomial

3. Mencari kekonvergenan metode standar trinomial dan enhanced trinomial pada barrier options pricing.

4. Membandingkan kecepatan kekonvergenan metode standar trinomial dan metode enhanced trinomial barrier options pricing. 


\section{HASIL DAN PEMBAHASAN}

\section{Metode Trinomial Barrier Option Pricing}

Pergerakan harga saham metode trinomial terdapat tiga kemungkinan yaitu harga saham naik $S u$, harga saham tetap $S$, dan harga saham turun $S d$. Dengan peluang naik $p_{u}$, peluang tetap $p_{m}$, dan peluang turun $p_{d}$, sehingga persamaan singkatnya adalah

$$
S(t+\Delta t)=\left\{\begin{array}{lr}
S(t) u, & \text { dengan peluang } p_{u} \\
S(t), & \text { dengan peluang } p_{m} \\
S(t) d, & \text { dengan peluang } p_{d}
\end{array}\right.
$$

Persamaan pergerakan harga saham secara umum pada saat $t=M$ menjadi

$$
S_{i, j}(t+\Delta t)=S(t) u^{i} d^{i}
$$

dengan $j=0,1,2,3, \ldots M$ dan $i=0,1,2, \ldots j+1$.

Nilai ekspektasi secara diskrit dari metode trinomial yaitu,

$$
E\left(S_{i+1}\right)=p_{u} S_{i} u+p_{m} S_{i}+p_{d} S_{i} d
$$

dan ekspektasinya secara kontinu yaitu,

$$
E\left(S_{i+1}\right)=S_{i} e^{r \Delta t}
$$

Sedangkan variansinya secara diskrit yaitu,

$$
\begin{aligned}
\operatorname{Var}\left(S_{i+1}\right) & =E\left(S_{i+1}^{2}\right)-\left(E\left(S_{i+1}\right)\right)^{2} \\
& =S_{i}^{2}\left(p_{u} u^{2}+p_{m}+p_{d} d^{2}\right)-S_{i}^{2}\left(p_{u} u+p_{m}+p_{d} d\right)^{2} \\
& =S_{i}^{2}\left(p_{u} u^{2}+p_{m}+p_{d} d^{2}\right)-e^{2 r \Delta t}
\end{aligned}
$$

dan secara kontinu yaitu,

$$
\begin{aligned}
\operatorname{Var}\left(S_{i+1}\right) & =E\left(S_{i+1}^{2}\right)-\left(E\left(S_{i+1}\right)\right)^{2} \\
& =S_{i}^{2} e^{\left(2 r+\sigma^{2}\right) \Delta t}-\left(S_{i} e^{r \Delta t}\right)^{2} \\
& =S_{i}^{2} e^{2 r \Delta t}\left(e^{\sigma^{2} \Delta t}-1\right)
\end{aligned}
$$

Penentuan parameter metode trinomial dilakukan dengan menetapkan nilai peluang tetap $p_{m}=2 / 3$, selanjutnya dengan menyamakan ekspektasi diskrit dengan kontinu dan variansi diskrit dengan kontinu didapatkan nilai-nilai parameternya sebagai berikut

$$
\begin{gathered}
p_{u}=\frac{1}{6}+\left(r-\frac{1}{2} \sigma^{2}\right) \sqrt{\frac{\Delta t}{12 \sigma^{2}}} \\
p_{d}=\frac{1}{6}-\left(r-\frac{1}{2} \sigma^{2}\right) \sqrt{\frac{\Delta t}{12 \sigma^{2}}} \\
u=e^{\sigma \sqrt{3 \Delta t}} \\
d=e^{-\sigma \sqrt{3 \Delta t}}
\end{gathered}
$$

Metode enhanced trinomial didapatkan dari nilai upper dan lower barrier yang terdapat pada selang nilai barrier. Dengan menggunakan persamaan (17) untuk harga saham yang positif ketika di atas nilai barrier dan persamaan (18) untuk harga saham yang positif ketika di bawah nilai barrier, sehingga didapatkan nilai opsi saham baru yang lebih kecil. 


\section{Simulasi dan Kekonvergenan Metode Enhanced Trinomial Barrier Options Pricing}

Pada simulasi ini dimisalkan harga saham awal $S_{0}=\$ 95$, harga kesepakatan $K=$ $\$ 100$, nilai barrier $B=\$ 125$, faktor bunga bebas risiko $r=0,1$, volatilitas $v=0,25$, waktu $T=1$ tahun, banyaknya iterasi $M=160$, dan nilai error maksimal $\varepsilon=5 \times 10^{-5}$. Selanjutnya disimulasikan up-and-out barrier options pricing untuk jenis call dan put option, sehingga didapatkan pergerakan konvergensi nilai opsi untuk setiap iterasi pada gambar berikut,

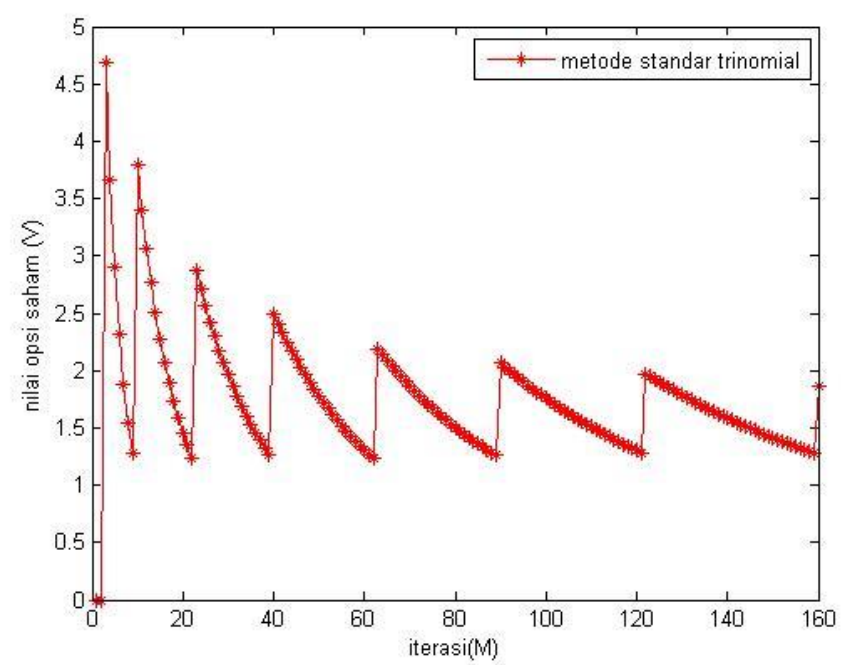

Gambar 2 Konvergensi Up-and-Out Call Option dengan Metode Standar Trinomial

Gambar 2 di atas menunjukan pergerakan konvergensi nilai opsi saham dengan metode standar trinomial dengan 160 iterasi. Karena disimulasikan up-and-out call option, maka digunakan rumus pada persamaan (18) untuk mencari nilai opsi saham dengan metode enhanced trinomial. Sehingga didapatkan konvergensi nilai opsi saham yang lebih kecil seperti gambar berikut

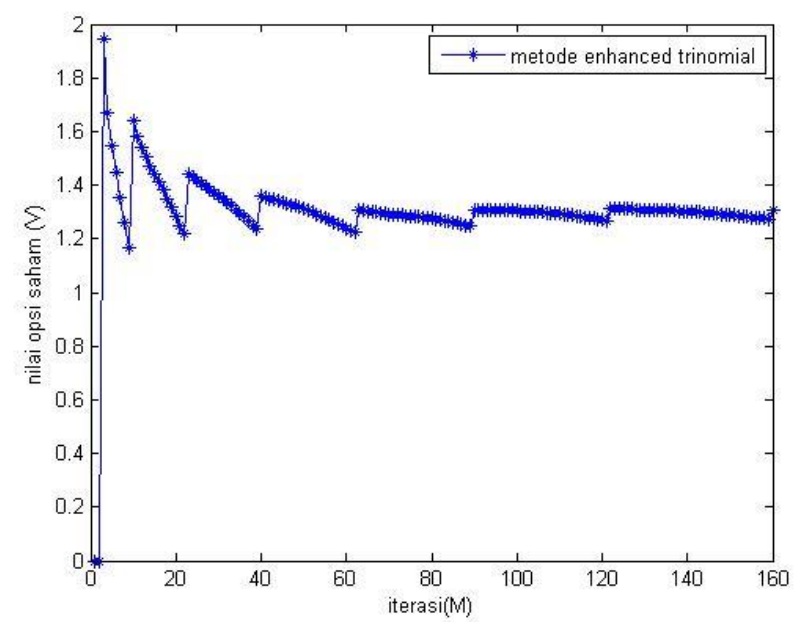

Gambar 3 Konvergensi Up-and-Out Call Option dengan Metode Enhanced Trinomial

Pada Gambar 3 di atas menunjukan pergerakan konvergensi nilai opsi saham upand-out call option dengan metode enhanced trinomial. Ketika iterasi ke-160 didapatkan nilai opsi saham $V_{0}=1,307106707$. Nilai opsi saham yang didapatkan lebih kecil 
daripada nilai opsi saham dengan menggunakan metode standar trinomial. Selanjutnya untuk simulasi up-and-out put option ditunjukan pada gambar berikut,

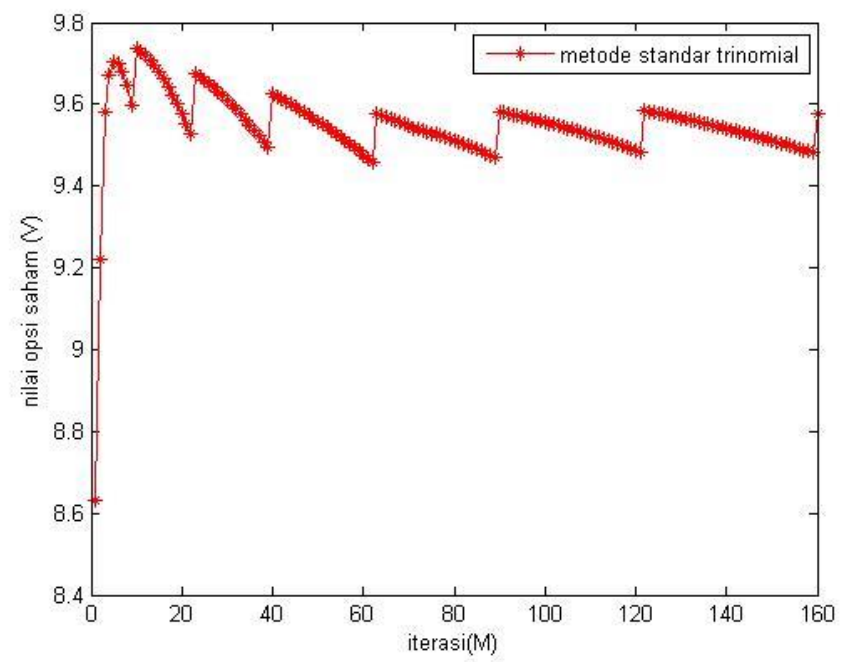

Gambar 4 Konvergensi Up-and-Out Put Option dengan Metode Standar Trinomial

Gambar 4 menunjukan pergerakan konvergensi nilai opsi saham Up-and-Out Put Option sampai iterasi ke 160. Dengan menggunakan metode standar trinomial didapatkan nilai opsi saham saat iterasi ke 160 yaitu $V_{0}=9$,575832. selanjutnya dengan menggunakan persamaan (18) didapatkan konvergensi nilai saham yang lebih kecil seperti gambar berikut

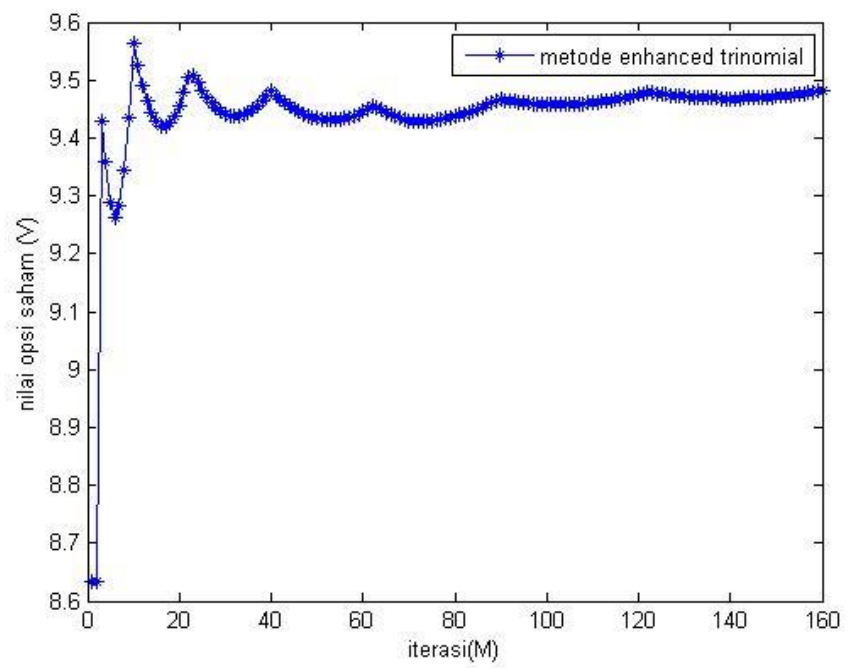

Gambar 5 Konvergensi Up-and-Out Put Option dengan Metode Enhanced Trinomial

Gambar 5 di atas menunjukan pergerakan konvergensi nilai opsi saham up-and-out put option. pada simulasi tersebut didapatkan nilai opsi ketika iterasi ke-160 adalah $V_{0}=$ 9,4803459. Selanjutnya untuk perbandingan kekonvergenan pada simulasi up-and-out untuk jenis call dan put option didapatkan grafik perbandingan kekonvergenan sebagai berikut, 


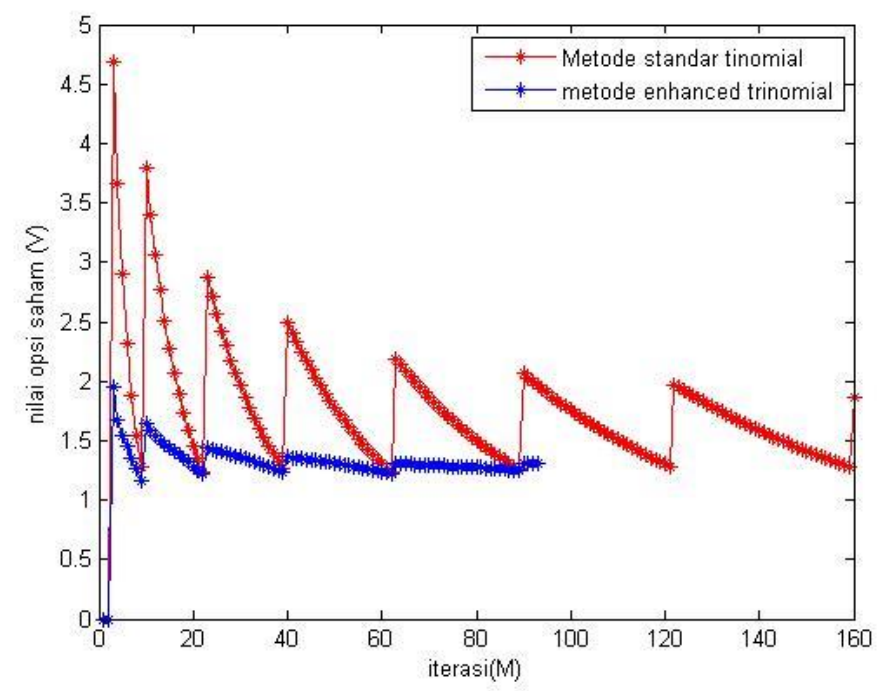

Gambar 6 Kekonvergenan Up-and-Out Call Option dengan Menggunakan Metode Standar Trinomial dan Metode Enhanced Trinomial

Dari Gambar 6 didapatkan bahwa simulasi metode standar trinomial belum konvergen sampai iterasi ke-160. Sedangkan dengan menggunakan metode enhanced trinomial sudah konvergen pada iterasi ke-93.

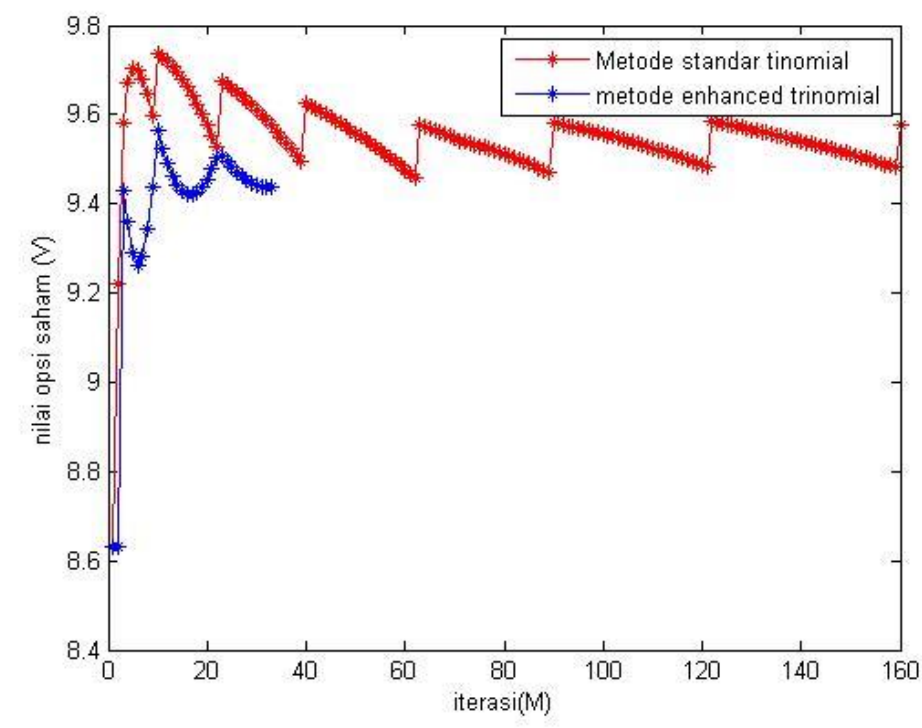

Gambar 7 Kekonvergenan Up-and-Out Put Option dengan Menggunakan Metode Standar Trinomial dan Metode Enhanced Trinomial

Dari Gambar 7 di atas didapatkan bahwa metode standar trinomial belum konvergen sampai iterasi ke-160. Sedangkan untuk metode enhanced trinomial sudah konvergen pada iterasi ke-33. Sehingga dapat disimpulkan bahwa dengan menggunakan metode enhanced trinomial lebih cepat konvergen daripada menggunakan metode standar trinomial. 


\section{KESIMPULAN}

Berdasarkan pemaparan di atas, maka diperoleh beberapa kesimpulan mengenai metode enhanced trinomial barrier option pricing sebagai berikut

1. Dengan menggunakan metode trinomial didapatkan 3 kemungkinan pergerakan nilai saham, yaitu harga saham naik, harga saham tetap, dan harga saham turun. Dengan persamaan parameter-parameternya yaitu $p_{u}=\frac{1}{6}+\left(r-\frac{1}{2} \sigma^{2}\right) \sqrt{\frac{\Delta t}{12 \sigma^{2}}}, p_{d}=\frac{1}{6}+(r-$ $\left.\frac{1}{2} \sigma^{2}\right) \sqrt{\frac{\Delta t}{12 \sigma^{2}}}, p_{m}=2 / 3, u=e^{\sigma \sqrt{3 \Delta t}}$, dan $d=e^{-\sigma \sqrt{3 \Delta t}}$.

2. Hasil simulasi dengan menggunakan metode standar trinomial didapatkan konvergensi nilai opsi saham untuk up-and-out call option pada iterasi ke-160 yaitu $V_{0}=1,870175$ dan up-and-out put option yaitu $V_{0}=9,575832$. Sedangkan untuk metode enhanced trinomial didapatkan konvergensi nilai opsi saham up-and-out call option pada iterasi ke-160 yaitu $V_{0}=1,307106707$ dan up-and-out put option yaitu $V_{0}=9,480345936$.

3. Simulasi up-and-out untuk jenis call dan put option dengan menggunakan metode standar trinomial belum konvergen sampai iterasi ke-160. Sedangkan simulasi up-andout call option dengan metode enhanced trinomial konvergen pada periode ke-93 dengan nilai error $\varepsilon=0,000046690289$. Dan untuk simulasi up-and-out put option dengan metode enhanced trinomial konvergen pada periode ke-33 dengan nilai error $\varepsilon=0,0000493988$.

\section{DAFTAR RUJUKAN}

[1] A. Aziz, Komputasi Numerik dengan Metode Kombinatorial untuk Barrier Options Pricing, Bandung: ITB, 2005.

[2] A. Aziz, "Empat Model Aproksimasi Binomial Harga Saham Model Black-Scholes," Cauchy: Jurnal matematika murni dan aplikasi, vol. 1, 2009.

[3] G. N. H. Mendes, Valuation of Barrier options Throught Trinomial Trees, Lisbon: Instituto Universitario De Lisboa, 2011.

[4] E. Derman, I. Kani, D. Ergener and I. Bardhan, "Enhanced Numerical Methods for Options with Barriers," Quantitatives Strategies Research Notes. Goldman Sacchs, 1995.

[5] S. Chapra and R. Canale, Numerical Methods for Engineers Sixth Edition, New York: McGraw-Hill, 2010. 